\title{
Survey of gastroenteritis in children admitted to hospital in Newcastle upon Tyne in 1971-5
}

\author{
C R PULLAN, H DELLAGRAMMATIKAS， H STEINER
}

British Medical fournal, 1977, 1, 619-621

\begin{abstract}
Summary
In a survey of 674 children admitted to the main gastroenteritis unit in Newcastle upon Tyne from 1971 to 1975 there was a noticeable reduction in the incidence of severe dehydration and hypernatraemia, though there was no appreciable change in many characteristics of the patients. This period coincided locally (and nationally) with a determined effort on the part of health visitors and doctors to encourage mothers to breast-feed and to advise them to avoid giving concentrated milk feeds and ensure an adequate water intake during febrile illnesses. This may have contributed towards a reduction in the severity of the illness in children with gastroenteritis admitted to hospital. The overall mortality and the incidence of neurological complications in cases of hypernatraemia are low compared with previous reports.
\end{abstract}

\section{Introduction}

Gastroenteritis is still an important cause of ill health and death in young children. Recent advances in our understanding and management of this condition include the identification of rotor viruses as an important cause of the disease, ${ }^{1}$ a greater under-

\footnotetext{
Fleming Memorial Hospital for Sick Children and the University of Newcastle upon Tyne, Newcastle upon Tyne NE2 3BD

C R PULLAN, MB, MRCP, paediatric registrar

H DELLAGRAMMATIKAS, MD, paediatric registrar

H STEINER, MRCP, DCH, senior lecturer in child health
}

standing of the dangers of giving concentrated milk feeds to children with diarrhoea, ${ }^{2}$ and improvements in treating the hyperosmolar hypernatraemic form of dehydration, ${ }^{3-5}$ which is such a common feature of gastroenteritis in Britain. ${ }^{6}$ Ironside et $a l^{7}$ in a large series from Manchester that included 112 dehydrated cases, reported an incidence of hypernatraemia (serum $\mathrm{Na}>150 \mathrm{mmol}(\mathrm{mEq}) / \mathrm{l})$ of $63^{\circ}{ }_{0}$ in the 75 cases in which electrolyte levels were measured.

We undertook this survey because it was our strong clinical impression that during the last few years the number of children admitted to hospital in Newcastle upon Tyne with severe gastroenteritis, and in particular with hypernatraemia, had been greatly reduced. This period coincided with a concerted local attempt by health visitors, general practitioners, child health clinic doctors, and paediatricians to educate and advise mothers on the correct procedure for making up feeds during health and disease, ${ }^{*}$ to study the reasons why mothers are reluctant to breast-feed, ${ }^{910}$ and to encourage breast-feeding whenever possible in view of its well-known protection against infections. ${ }^{112}$

\section{Methods}

We analysed information recorded in the case notes of all children admitted to the gastroenteritis unit of the Fleming Memorial Hospita for Sick Children, Newcastle upon Tyne, from 1971 to 1975. During that time, most children who needed hospital treatment for this condition and who were resident in Newcastle and surrounding parts of Northumberland were admitted to this unit. We have included all children who had diarrhoea as the main presenting symptom with or without vomiting. In addition to signs and symptoms of gastroenteritis, some children had infection elsewhere, such as of the upper respiratory tract, and these have also been included.

A standard procedure was adopted for assessing the severity of dehydration, similar to that described by Ironside et al, and for the further investigation and management of all cases (see appendix). Serum electrolyte concentrations were usually estimated in all 
moderately and severely dehydrated cases but not as a routine in the mild ones. Stool cultures were limited to identifying bacteria, and viruses were not sought as a routine. Hypernatraemia was defined as a serum $\mathrm{Na}$ of $150 \mathrm{mmol}(\mathrm{mEq}) / 1$ or more.

So far as the outcome is concerned, although no attempt was made to follow the progress of all the children after discharge from hospital it may safely be assumed that any evidence of major brain damage such as cerebral palsy would have been evident on discharge home.

\section{Results and comment}

During 1971-5 there were 674 admissions to the gastroenteritis unit. The age, social class, length of history of diarrhoea and vomiting, and the medication given before admission are shown in table I. There were no appreciable changes in any of these findings during the years of the survey. In contrast, there was a considerable and progressive decrease in the incidence of severe dehydration from $31.1^{\circ}$ in 1971 to $4.1 \%$ in 1975 and hypernatraemia from $27.6^{\circ}$ o in 1971 to $12.5^{\circ} \%$ in 1975 in cases in which serum electrolyte levels were estimated. The proportion of moderately severely dehydrated cases and lesser degrees of hypernatraemia (serum Na $145-149 \mathrm{mmol}(\mathrm{mEq}) / \mathrm{l}$ ) also decreased. By 1975, the total number of cases of hypernatraemia identified in the unit was down to $7\left(4 \cdot 8^{\circ}\right)$ of all cases admitted compared with 27 $(25.5 \%)$ in 1971 (tables II and III).

Bacteria were isolated in $55\left(8.2^{\circ}{ }_{0}\right)$ cases including pathogenic Escherichia coli 28, Shigella sonnei 20, Salmonellas 3 (typhimurium 1, agona 1 , oram 1), Pseudomonas pyocyanea 2 , Proteus 1 , and Streptococcus viridans 1 . Infections in other parts of the body were recorded in 177

TABLE I-Age, social class, length of history, and medication for 674 cases of gastroenteritis before admission to Fleming Hospital 1971-5

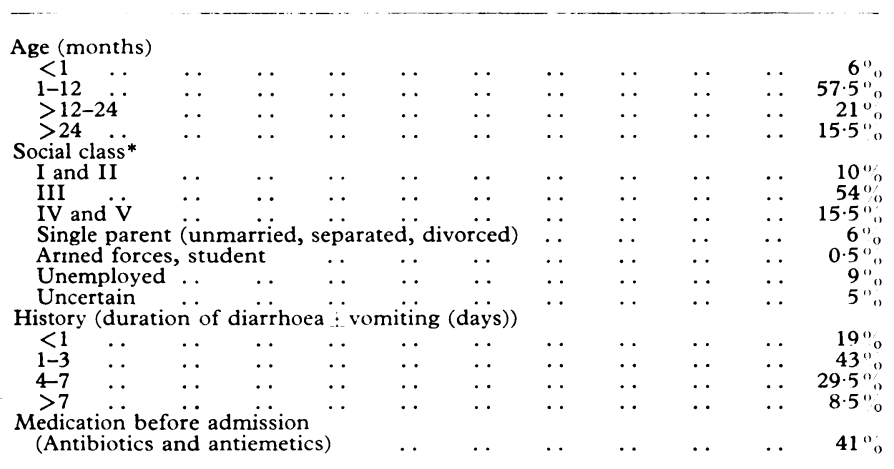

*General Register Office of Classifications of Occupations (1966)

TABLE II-Severity of dehydration in 674 cases of gastroenteritis at the Fleming Hospital, 1971-5

\begin{tabular}{|c|c|c|c|c|c|}
\hline \multirow{3}{*}{ Year } & \multirow{3}{*}{$\begin{array}{l}\text { Total No } \\
\text { of cases }\end{array}$} & \multicolumn{4}{|c|}{ Severity of dehydration } \\
\hline & & None & Mild & Moderate & Severe \\
\hline & & No $(\%)$ & No $\left({ }^{\circ}{ }_{0}\right)$ & No $\left(\begin{array}{l}0 \\
0\end{array}\right)$ & No $\left({ }^{\circ}{ }_{11}\right)$ \\
\hline $\begin{array}{l}1971 \\
1972 \\
1973 \\
1974 \\
1975\end{array}$ & $\begin{array}{l}106 \\
120 \\
161 \\
142 \\
145\end{array}$ & $\begin{array}{l}20(18.9) \\
36(30.0) \\
90(55.9) \\
79(55.6) \\
88(60.7)\end{array}$ & $\begin{array}{l}16(15 \cdot 1) \\
34(28 \cdot 3) \\
44(27 \cdot 3) \\
40(28 \cdot 2) \\
30(20 \cdot 7)\end{array}$ & $\begin{array}{l}37(34 \cdot 9) \\
30(25 \cdot 0) \\
15(9 \cdot 3) \\
20(14 \cdot 1) \\
21(14 \cdot 5)\end{array}$ & $\begin{array}{c}33(31 \cdot 1) \\
20(16 \cdot 7) \\
12(7 \cdot 5) \\
3(2 \cdot 1) \\
6(4 \cdot 1)\end{array}$ \\
\hline
\end{tabular}

TABLE III-Serum sodium levels in patients with gastroenteritis at the Fleming Hospital, 1971-5

\begin{tabular}{|c|c|c|c|c|c|c|}
\hline \multirow{3}{*}{ Year } & \multicolumn{6}{|c|}{ Serum sodium levels $\mathrm{mmol}(\mathrm{mEq}) / 1$} \\
\hline & \multirow{2}{*}{$\begin{array}{c}\text { No not } \\
\text { estimated }\end{array}$} & \multirow{2}{*}{ estimated } & $<130$ & $130-144$ & $145-149$ & $>150$ \\
\hline & & & No $(\%)$ & No $\left({ }^{\prime \prime}{ }_{0}\right)$ & No $(\%)$ & No $\left(0_{0}^{0}\right)$ \\
\hline $\begin{array}{l}1971 \\
1972 \\
1973 \\
1974 \\
1975\end{array}$ & $\begin{array}{r}8 \\
16 \\
41 \\
62 \\
89\end{array}$ & $\begin{array}{r}98 \\
104 \\
120 \\
80 \\
56\end{array}$ & $\begin{array}{l}2(2 \cdot 0) \\
2(1 \cdot 9) \\
2(1 \cdot 6) \\
2(2 \cdot 5) \\
4(7 \cdot 1)\end{array}$ & $\begin{array}{l}55(56 \cdot 1) \\
52(50.0) \\
81(67.5) \\
70(87.5) \\
42(75.0)\end{array}$ & $\begin{array}{c}14(14 \cdot 3) \\
28(26 \cdot 9) \\
17(14 \cdot 2) \\
6(7 \cdot 5) \\
3(5 \cdot 4)\end{array}$ & $\begin{array}{c}27(27 \cdot 6) \\
22(21 \cdot 2) \\
20(16 \cdot 7) \\
2(2 \cdot 5) \\
7(12 \cdot 5)\end{array}$ \\
\hline
\end{tabular}

cases, including upper respiratory tract infections 164 , bronchiolitis 4 , pneumonia 2, urinary tract infections 6, and meningitis (Listeria monocytogenes) 1 . One child also had fibrocystic disease and one an intussusception. The types of bacteria isolated from the stools and the other infections did not differ significantly over the years.

So far as the outcome is concerned, the incidence of temporary cows' milk intolerance decreased from $10^{\circ}$ " in 1971 to $4^{\circ}{ }^{\circ}$ in 1972 , $3^{\circ}{ }_{0}$ in $1973,2.5^{\circ}{ }_{0}$ in 1974 , and $1.5^{\circ}{ }_{0}$ in 1975 . All these children recovered completely and were able to tolerate cows' milk and ordinary food within six weeks of discharge from hospital.

Five $\left(0 \cdot 74^{\circ}{ }^{\prime}\right)$ children had convulsions after admission to hospital. Three of them were hypernatraemic, an incidence of $3.8^{\circ} \%$ in this group of 78 cases. Convulsions occurred within four hours of admission in three children, and these were thought to be febrile because they occurred only on one occasion, lasted only a few minutes, and were associated with a high fever of over $38.5 \mathrm{C}$. One hypernatraemic baby developed convulsions lasting a few minutes about 24 hours after admission, and another severely dehydrated baby with a serum sodium concentration of over $160 \mathrm{mmol}(\mathrm{mEq}) / 1$ had already convulsed before admission to hospital; she continued to do so intermittently for several weeks despite massive doses of anticonvulsants; she became severely developmentally retarded, and died three months later. Four $\left(0.59^{\prime \prime}{ }^{\prime}\right)$ died in hospital. One of them had a severe cardiac malformation. The others were moribund on arrival and died soon afterwards despite vigorous attempts at resuscitation.

\section{Discussion}

Since 1971, in Newcastle upon Tyne, the incidence of severe gastroenteritis has fallen sharply, as indicated by a decrease in the incidence of severe dehydration and hypernatraemia and in the proportion of children who developed temporary cows' milk intolerance. (Preliminary findings in the first six months of 1976 suggest that this trend has been maintained.)

We do not know of any notable change in age distribution, social class, bacteria isolated from stools, nor indeed in length of history or the amount and type of medication given before admission to hospital. We have no reliable information about viruses as a possible cause of the disease because these were not routinely sought during the early years of the survey. The virulence of the causal agents might have changed, but it is also likely that recent local attempts at improving the advice given to mothers on the optimal methods of feeding young children including breast-feeding ${ }^{13}$ and the need to ensure an adequate water intake during febrile illnesses have played an important part. A recent survey of infants attending child health clinics in Newcastle supports this impression. In a sample of 50 healthy infants Dale et al $^{14}$ found a lower incidence of hyperosmolality than that previously reported ${ }^{15}$ and no appreciable difference in the plasma sodium concentration of breast-fed compared with bottle-fed infants.

Despite the fall in the number of severe cases of gastroenteritis there has been no reduction in the total number of cases admitted to hospital from 1971 to 1975 . Indeed, the number of children who were not dehydrated on admission has substantially increased. We do not have a conclusive explanation for these findings, but believe that possibly, along with a greater understanding of the needs of ill children, there has also been a greater awareness of the dangers of dehydration, and that this may well have led to a lower threshold for referral to hospital.

All but a handful of children made a complete recovery. All children with cows' milk intolerance recovered. The incidence of convulsions $\left(3.8^{\circ}\right.$ ) after admission to hospital and later severe brain damage (one case) in children with hypernatraemia is low compared with reports on these kinds of sequelae in $9-18 \%$ of cases. ${ }^{31617}$ These results were achieved despite a relatively simple form of management that did not include the use of complex electrolyte solutions or the correction of acidosis.

It remains to be seen whether further improvements in the outlook for young children with gastroenteritis can be achieved by more intensive education of parents on the appropriate care of their children, which ought to include a strong emphasis on the benefits of breast-feeding. 
Now that most cases in our community have only the milder forms of the disease, it also seems appropriate to consider the indications for admission to hospital with all the attendant disruptions to family life. It may be that the introduction of a comprehensive paediatric home nursing scheme in our area, similar to that in nearby Gateshead, " would result in a diminishing need for hospital admission.

\section{Appendix}

MANAGEMENT OF CHILDRFN WITH DIARRHOEA AND VOMITING AT THE FLEMING HOSPITAL, 1971-5

(1) Clinical assessment of the degree of dehydration based on the length of the history of diarrhoea and vomiting, the fluid intake, skin turgor, dryness of mucous membranes, state of peripheral circulation, and blood pressure. " Degrees of dehydration are mild $\left(2 \cdot 5-5^{\prime \prime}\right.$ "loss of body weight), moderate (over 5-10 ${ }^{\circ}$ ), and severe (over 10" ${ }^{\prime \prime}$ ).

(2) Assessment of basic fluid requirements: age less than 6 months (150 $\mathrm{ml} \mathrm{kg} \mathrm{body} \mathrm{weight} 24$ hours), $6-12$ months ( $140 \mathrm{ml} \mathrm{kg} 24 \mathrm{~h}$ ), and over 12 months $(120 \mathrm{ml} \mathrm{kg} 24 \mathrm{~h})$.

(3) Fluids by mouth 3-4 hourly, consisting initially of $5 \mathrm{M}$ saline 4 " dextrose, to children with mild or no dehydration.

(4) Intravenous treatment (and nil by mouth) initially for all but mildest cases.

(a) Poor peripheral circulation and low blood pressure-plasma 20 $\mathrm{ml} \mathrm{kg}$ body weight fast, then continue as in $(b),(c)$, or $(d)$, allowing for the amount of plasma already given.

(b) Hypernatraemia (scrum $\mathrm{Na} 150 \mathrm{mmol}$ (mEq) 1)-relatively slow rehydration over 48 hours with $5 \mathrm{M}$ saline $4{ }^{\prime \prime}{ }_{\text {" }}$ dextrose; $\mathrm{ml}$ hour =estimated volume required to correct dehydration + (basic requirements per 24 hours 2) 48 .

(c) Hyponatraemia (serum $\mathrm{Na}<130 \mathrm{mmol}(\mathrm{mEq})$ 1)-rehydration over 24 hours with appropriate amounts of isotonic normal, halfnormal, or one-fifth-normal saline.

(d) Serum Na 130-149 mmol (mEq) l-rehydration over 24 hours with $5 M$ saline 4 " "dextrose.

(5) Potassium chloride $30 \mathrm{mmol}(\mathrm{mEq}) \mathrm{l}$ in intravenous fluids as soon as urine flow established.

(6) No attempt was made to correct acidosis.

(7) Antibiotics were not given as a routine. They were reserved for babies with clinical features suggestive of septicaemia and for children with specific conditions such as urinary tract infections.

(8) After intravenous treatment, which was usually continued for
24-48 hours, feeds were given by mouth every 3-4 hours starting with $5 \mathrm{M}$ saline $4^{\prime \prime}$ "dextrose and continuing with cows' milk at increasing concentrations of a quarter, half, and three-quarters strengh. The strength of feeds was increased every 12-24 hours.

(9) If diarrhoea recurred after introduction of oral feeds the stools were tested for sugar and $\mathrm{pH}$, and the child was put back on $5 \mathrm{M}$ saline 4 ". dextrose by mouth, and a second attempt was made to give cows' milk of increasing concentrations.

Cows' milk intolerance was diagnosed after a second relapse, which was treated with increasing concentrations of Sobee (Mead Johnson). Galactomin (Cow and Gate) was used if it could be clearly established that there was a disaccharide intolerance. Treatment was continued, with the addition of Ketovite, for one month, when cows' milk was slowly substituted.

We are grateful to the late Dr Gerald Neligan for his advice and encouragement and the nursing staff of the Fleming Hospital who looked after the children.

\section{References}

${ }^{1}$ British Medical fournal, 1975, 3, 555.

2 Taitz, L S, and Byers, H D, Archives of Disease in Childhood, 1972, 47, 257.

${ }^{3}$ Habel, A H, and Simpson, H, Archives of Disease in Childhood, 1976, 51, 660.

Finberg, L, New English fournal of Medicine, 1973, 289, 196.

5 Banister, A, Matin-Siddique, S A, and Hatcher, G W, Archives of Disease in Childhood, 1975, 50, 179.

${ }^{6}$ Macaulay, D, and Blackhall, M I, Archives of Disease in Childhood, 1961, 36, 543 .

'Ironside, A G, Tuxford, A F, and Heyworth, B, British Medical fournal, 1970, 3, 20 .

${ }^{8}$ Wilkinson, P W, et al, British Medical fournal, 1973, 2, 15.

${ }^{9}$ Eastham, E, et al, British Medical fournal, 1976, 1, 305.

10 Bacon, C J, and Wyllic, J M, British Medical fournal, 1976, 1, 308.

${ }^{11}$ Bullen, C L, and Willis, A T, British Medical fournal, 1971, 3, 338

12. Downham, M A P S, et al, British Medical fournal, 1976, 2, 274.

${ }^{13}$ Department of Health and Social Security. Report on Health and Social Subjects. 9. Present-day Practice in Infant Feeding. London, DHSS, 1974.

${ }^{14}$ Dale, G, et al, Archives of Disease in Childhood, 1975, 50, 731

1: Davies, D P, British Medical fournal, 1973, 2, 340.

${ }^{16}$ Macaulay, D, and Watson, M, Archives of Disease in Childhood, 1967, 42, 485.

Morris-Jones, P H, Houston, I B, and Evans, R C, Lancet, 1967, 2, 1385.

is Jackson, H, 1976, personal communication.

(Accepted 15 December 1976)
I have had several patients in the past year with group A streptococcal infection of the throat. Some of these, including some middle-aged men, developed acute rheumatism. What investigations and treatment are recommended?

Swabs of nose, throat, and skin should be taken for isolation of streptococci. If these cannot reach the laboratory within two hours they should be dispatched in a carrier medium (such as Stuart's) or rubbed on filter paper and the well-dried paper enclosed in a separate envelope. Not all group A streptococci appear beta-haemolytic on first isolation, especially in aerobic culture. Anaerobic culture is thus always desirable. If group A streptococci are present, or reappear, penicillin for 10-14 days is needed to prevent rheumatic complications, even though most cocci may be killed and local infection controlled by only four day's treatment. All group A (but not all beta-haemolytic) streptococci are always sensitive to penicillin. In about $10^{\circ}{ }_{0}$ of patients, however, cocci persist even after 10 days' treatment. Penicillinaseproducing staphylococci are not normally responsible for this but at times their presence may completely abolish the therapeutic effect of penicillin. When feasible, the titre of antibodies to streptococcal products should be estimated at intervals. Almost all patients with rheumatic fever have antibody of some kind even though only $50-80^{\prime \prime}$ " have raised titres to any particular antigen, and many patients with raised titres never develop any rheumatic complication. In nontropical places, patients less than 18 years old; those with a previous history of rheumatic carditis or other complication; and those with high or rising antibodies have a much increased risk of rheumatic fever. In tropical countries the same relations almost certainly hold but here the incidence appears relatively greater in those aged under
5 ; the results of throat cultures are less often positive, whereas cultures from the skin, with or without impetigo, are more often positive; and carditis, quite often rapidly progressive, is the most usual complication. ${ }^{1}$ In all countries, therefore, recurrent streptococcal infection should be prevented so far as possible by long-term chemoprophylaxis with three-weekly benzathine benzylpenicillin intramuscularly or daily phenoxymethylpenicillin by mouth. ${ }^{23}$ In the absence of heart damage this should be continued for five years or until the child leaves school. In its presence prophylaxis should be continued up to the age of 18 and thereafter according to the estimated risk of reinfection. This will be greater the more the patient is in contact with young children and young adults and obviously proportional to the local streptococcal carriage rate and infection rate. At times, and with a first attack of rheumatic fever in an adult, screening all close contacts (largely family and kissing contacts, but at times all classmates) for streptococci should be considered-for the benefit of the contacts as well as that of the patient.

1 Shaper, A G, British Medical fournal, 1972, 2, 683 .
2 Ministry of Health, Prevention of Initial Attacks and Recurrence of Rheumatic
Fever. London, HMSO, 1960 .
3 Feinstein, A R, et al, Fournal of the American Medical Association, 1968, 206, 565.

A young woman suffered a thrombosis in an arm vein after an intravenous injection during an operation for termination of pregnancy. Does this indicate any predisposition to thrombosis and should she avoid oral contraceptives?

The answer is no to both questions. 